\title{
Development of Solar Desalination Units Using Solar Concentrators or/and Internal Reflectors
}

\author{
Mokhtar Mohammed*, Taha Janan Mourad \\ National School of Arts and Professions, High National School of Computer Science and Systems Analysis, \\ Mohammed V University, Rabat, Morocco \\ Received 17 August 2021; received in revised form 02 October 2021; accepted 03 October 2021 \\ DOI: https://doi.org/10.46604/ijeti.2021.8304
}

\begin{abstract}
Solar distillation is one of the oldest and simplest technologies for desalination of salty water using renewable energy, namely solar energy, and the main problem of solar distillers is the low freshwater yield in contrast to the amount of energy input from the sun. To overcome the problem, this study develops three solar desalination units by using solar concentrators or/and internal reflectors, and compares the performance of three developed systems with the one of a conventional solar distiller under the climatic conditions of the Rabat region of Morocco. The three systems are: the solar distiller with a solar concentrator, the solar distiller with internal reflectors, and the solar distiller with a solar concentrator and internal reflectors. The energy balance equations of the systems are numerically resolved to utilize MATLAB software. The findings indicate that the utilization of the internal reflectors, the solar concentrator, and the solar concentrator and internal reflectors give better performance compared to the conventional solar distiller.
\end{abstract}

Keywords: desalination, solar distiller, internal reflector, solar concentration

\section{Introduction}

Water scarcity is a daily challenge for people who live in remote places or islands where transporting freshwater is too expensive. Solar stills have special advantages for the use in these places due to the ease of manufacturing, the low-skilled operation and preservation, and the environmental responsiveness. Two important advantages that support the use of solar stills are that they are clean and environmentally friendly [1].

Desalination is the process of converting saline water into a usable form by removing salt, pollutants, and other mineral components. Desalination is a high-energy process. Energy is essential for economic and social growth. In comparison with traditional fossil fuel energy sources, which have negative environmental consequences, solar energy is readily available, simple to use, healthy, and renewable. This energy is regarded as one of the most promising fossil-fuel alternatives [2]. Faced with the freshwater crisis, solar distillation can be discovered to be a potential solution for converting brackish or brine water into clean water by utilizing the abundant and readily available solar energy on the Earth [3].

Scientists and researchers have been performed many studies and research to get alternative energy sources, and the results were very satisfactory. Many alternative sources of energy were replaced by conventional fuels as the use of solar energy was developed in many fields. With solar desalination devices, which work based on the evaporation and condensation

* Corresponding author. E-mail address: mohammed_mokhtarnomanqasem@um5.ac.ma Tel.: +212654866890; Fax: +212537686078 
principle, solar energy has been used to desalinate saltwater and generate potable water in an environmentally responsible way. However, the production of traditional solar distillers is insufficient. As a result, several researchers are adding new technologies to the traditional solar distiller system to increase the yield of freshwater [4-5].

To focus and collect solar radiation in one place to enhance its heating effect to the water to be desalinated, solar concentration techniques are used, as in this present research, including parabolic trough concentrators (PTCs). To increase the supply of solar radiation to solar distillers to increase the effective solar heat, solar distillers are developed using concentrators or/and reflectors. The strength of the effect of concentrators and reflectors on the solar distillers, in general, depends on the area of concentrators and reflectors and the reflection coefficients of the rays on their surfaces. Several design changes were done to enhance the solar distillers' performance. The internal walls of solar distillers were exploited by adding internal reflectors in this research to increase the amount of solar radiation and thus increase the temperature of the water and the basin for distillers.

The goal of this research is to develop the solar distillers with improved cumulative freshwater production by adding solar concentrators or/and internal reflectors to boost the amount of solar irradiation reaching the solar distillers, and to compare the performance of three developed systems with the one of the conventional solar distiller. The energy balance equations for all systems are constructed and solved using analytical methods for the essential components of systems to utilize MATLAB software. Numerical computations are performed under the same meteorological parameters in the Moroccan city of Rabat.

\section{Literature Review}

This section presents several changes that can be made to enhance the performance of conventional solar water desalination units, according to previous publications. To improve the thermal performance and freshwater yield of solar distillers, many researchers have proposed adding concentrator technology, e.g., PTCs, compound parabolic concentrators (CPCs), and compound conical concentrators (CCCs), while some researchers have proposed adding internal and/or external solar reflectors to solar distillers.

The most often used linear concentrators for solar thermodynamic conversion are PTCs, which are practically used in home and industrial settings when the working temperature is required around $80^{\circ} \mathrm{C}$ and $160^{\circ} \mathrm{C}$. PTCs are among the most extensively utilized innovations to supplant nonrenewable energy sources (fossil and nuclear fuels) in the manufacturing sectors, such as desalination, combination power stations, refrigeration, irrigation, and air conditioning [6-8].

Arunkumar et al. [9] compared three devices: a CCC, a CPC-tubular solar distiller (CPC-TSS), and a single-slope solar distiller. The daily output values of single-slope solar distiller, CPC-TSS, and CCC are 2,100, 6,100, and 18,000 per $\mathrm{m}^{2}$, respectively. The freshwater yield of CCC was the highest. Gharbi et al. [10] conducted a comparative analysis between collectors' parabolic trough and linear fresnel reflector (LFR). They discovered that due to a higher cosine factor and incidence angle effect, LFR has the worse optical quality and thermal performance, but it also has the lower prices.

Mulyanef et al. [11] carried out an experimental study of the reflector effect on the performance of solar distillers to generate salt and fresh water in the Padang city, Indonesia. According to the test data, the use of reflectors can raise the heat in the water basin. The yield of clean water rises, shortening the time it takes to produce salt. Umar and Muhammad [12] developed a solar still with a reflecting booster, and compared its performance to that of a normal (non-reflecting booster) solar still with the same technical parameters to examine how the reflecting booster affected the solar still's performance. The results suggested that the solar still with reflecting booster has a better performance than the normal solar still.

Al-Garni [13] carried out an experimental study of the distilled water yield in the winter using a double-slope solar still

with exterior reflectors. Four angled mirrors were used to focus the increased sun irradiance onto the solar still. Exterior reflectors have been demonstrated the solar still output, with a distillate rise of around $82 \%$ seen in this investigation. Khan and 
Mustafa [14] conducted an analytical study of the effects of all aspects of design and operation on the distilled water yield of solar stills, and they suggested adding a simple reflector to the top cover of conventional solar still. The findings were observed that the maximum distilled water yield was improved from 0.44 to 0.65 by using the proposed reflector.

Omara et al. [15] investigated how the different wick materials and reflectors affected the corrugated solar stills' performance with various brackish water depths $(1,2$, and $3 \mathrm{~cm})$. With different wick materials and reflectors, they found that the total output and efficiency of the corrugated solar stills were increased by $145.5 \%$ and $78.8 \%$, respectively. Khechekhouche et al. [16] tested the effect of using a simple external mirror to improve the traditional distiller's performance. When compared to the traditional distiller, the researchers discovered that employing the external reflective mirror increased the distilled water yield by $42.35 \%$.

Attia et al. [17] conducted an empirical analysis of energy, exergy, and economy of the hemispherical distillates with black painted walls (BPWs), reflective mirrors (RMs), and reflective aluminum foil sheets (RAFSs) installed on the vertical internal surfaces of distillers, and compared their effects on the hemispherical distillers' performance. The experimental results indicated that the utilization of RAFSs improved the cumulative yield and thermal efficiency by $42.3 \%$ and $37.5 \%$, respectively, compared to the use of BPWs. Also, the utilization of RMs improved the cumulative yield and thermal efficiency by $62.6 \%$ and $57.26 \%$, respectively, compared to the use of BPWs. The exergy efficiency of RMs and RAFSs was improved by $69.61 \%$ and $123.1 \%$, respectively, compared to that of BPWs. The economic study indicated that the cost of freshwater produced from RMs and RAFSs was reduced by $29 \%$ and $38 \%$, respectively, compared to the cost using BPWs.

An experimental study is presented by Gnanaraj and Velmurugan [18] on the usefulness of the adjustments in boosting the single-slope solar stills' performance. They developed three solar stills with inside alterations such as wicks, black granite, and finned corrugated basins, then manufactured other stills with exterior reflectors, and lastly constructed one still that was incorporated all of the above internal and external adjustments. The distilled water output of the still with black granite, with reflectors, with wicks, with finned corrugated basins, and with all internal and external adjustments were 3210, 3655, 2690, 2995 , and $5130 \mathrm{ml} / \mathrm{m}^{2}$. day, respectively, which were $69.84 \%, 93.39 \%, 42.33 \%, 58.47 \%$, and $171.43 \%$ higher than the conventional still.

Abdullah et al. [19] experimentally and theoretically studied a trays solar still (TSS) by using internal and external mirrors, and compared it with a conventional solar still (CSS). At 1 and $0.5 \mathrm{~cm}$ level of basin water and trays height, respectively, the TSS without reflectors had roughly 1.5 times the daily output of the CSS. The TSS with internal mirrors (TSSIM) showed a $58 \%$ increase in output over the CSS. Additionally, as compared to the CSS output, using external bottoms (TSSIBM) and top mirrors (TSSITM) increased TSSIM's productivity by $84 \%$ and 75\%, respectively. TSSIM's distilled water output was $95 \%$ higher than CSS's when both external bottoms and top mirrors (TSSIBTM) were used.

From the literature survey, it has been proven that adding one of the new technologies such as solar concentrators or internal and external reflectors to the conventional solar distillers leads to an increase in the yield of distilled water, and also that adding two or more technologies leads to a much higher yield of distilled water compared to adding one technology of the system.

\section{Design Modeling of Developed System}

In this study, solar desalination units are developed by using solar concentrators or/and internal reflectors. They are designed as a novel type of solar distillers based on the concentration with internal reflectors. The schematic diagram of a solar desalination unit with a solar concentrator and internal reflectors is shown in Fig. 1. The half-cylinder basin diameter of the distiller is $0.3 \mathrm{~m}$, fabricated from a black painted aluminum sheet with $0.004 \mathrm{~m}$ thickness and located in the focal line of PTC with $1 \mathrm{~m}$ from the vertex $(V), 1.25 \mathrm{~m}$ for the system aperture $(W)$, and $34.72^{\circ}$ for the system rim angle. 
The basin is designed in a half-cylindrical shape to help collect the water to be desalinated and also to help shed the sun's rays from the solar concentrator system on it. The inner walls of the solar distiller, two internal reflectors ( $3 \mathrm{~m}$ long and $0.3 \mathrm{~m}$ wide), and the other two internal reflectors $\left(0.3 \mathrm{~m}\right.$ long and $0.3 \mathrm{~m}$ wide) are installed. The total area of the internal reflectors is $1.98 \mathrm{~m}^{2}$. The external walls of the solar distiller are insulated by a $2 \mathrm{~cm}$ layer of sawdust contained in a wooden frame with $1 \mathrm{~cm}$ thickness.

A $0.36 \mathrm{~m} \times 3 \mathrm{~m}$ glass cover sits on the top surface of the solar distiller. The top cover is composed of a transparent glass with $0.002 \mathrm{~m}$ thickness. It places over the grooves with a double inclined $30^{\circ}$ angle. Freshwater collection segments with $3 \mathrm{~m}$ length and $0.030 \mathrm{~m}$ width are put at a suitable location. The ratio of concentration is the ratio of the area of the PTC aperture to the absorber area. The ratio of concentration for the unit is 2.65 .

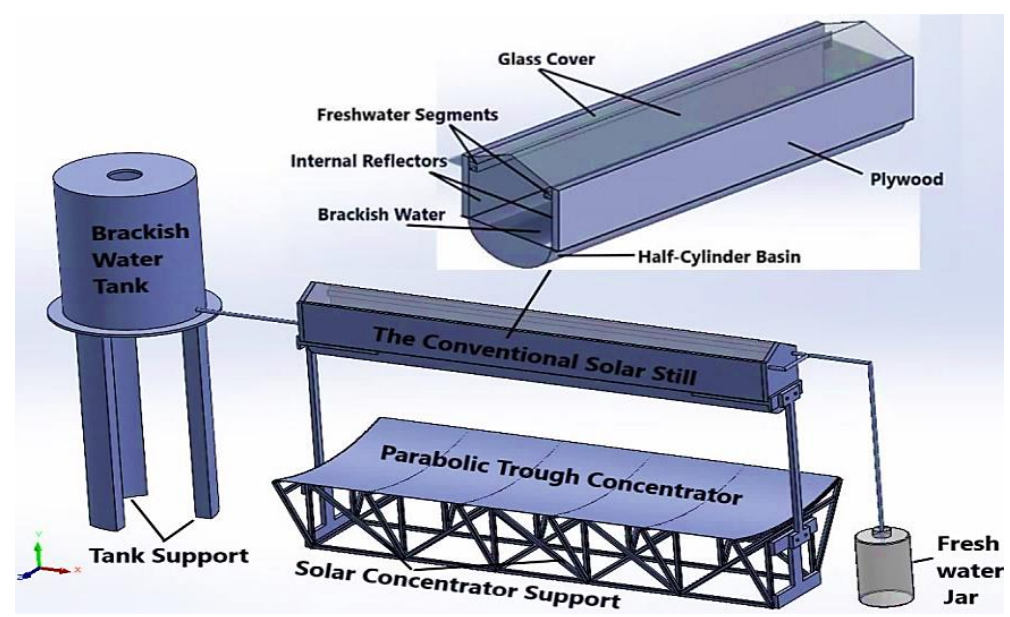

Fig. 1 Schematic view of a solar desalination unit with a solar concentrator and internal reflectors

\section{Energy Analysis and Heat Transfer}

Fig. 2 depicts the transversal view of the heat transfer pathways in the developed solar desalination unit through the system parts (i.e., an absorber basin, water, a glass cover, a solar concentrator, and internal reflectors). Solar irradiance will drop into the unit with two internal reflectors in two places:

(1) Solar irradiance will drop into the solar distillation device, where a small part of the solar radiation is absorbed by the glass cover and most of it transmits through the glass cover to the inside of the distiller. Some of the emitted irradiance are absorbed by the water and the absorber basin, and others fall on the internal reflectors located on the sides of the solar distiller where the radiation will be reflected in the water and absorber basin.

(2) Solar irradiance will drop into the solar concentrator, where the sunlight will be deflected to the absorber basin of the solar distiller. The center of the half-cylindrical absorber basin is the focal line of PTC. The concentration of solar irradiance on the absorber basin heats the water through convection and raises its temperature. By convection, the absorber basin loses little heat to the atmosphere once more.

The evaporation, convection, and radiation of water transfer the thermal obtained by the basin water to the internal glass surface in this process. Once heated, the water evaporates and rises until it reaches the internal glass cover layer. After that, the water vapor on the inside surface of the glass cover condenses and forms clean water, which is then collected in the segments on each side of the distiller. By convection and radiation, the glass cover dissipates the heat to the atmosphere once more. The temperature of the device's components is determined using the energy balance equations.

The following assumptions are used to create the energy balance equations [8]:

(1) The parabola has a symmetrical shape.

(2) The influence of the distiller shadow on the parabola is negligible. 
(3) The physical characteristics of various materials are constant.

(4) The side and bottom walls' heat capacity is ignored.

(5) The effect of the tilt of the glass cover is neglected.

(6) With the depth of the water and the thickness of the glass cover, a constant temperature gradient is maintained.

(7) Ideal gases include dry air and water vapor.

(8) There is no vapor leaking inside the device.

(9) The internal glass-cover surface is the only place where condensation occurs.

(10) The level of water in the half-cylinder basin remains constant.

(11) Segmental and wall-side losses are not taken into account.

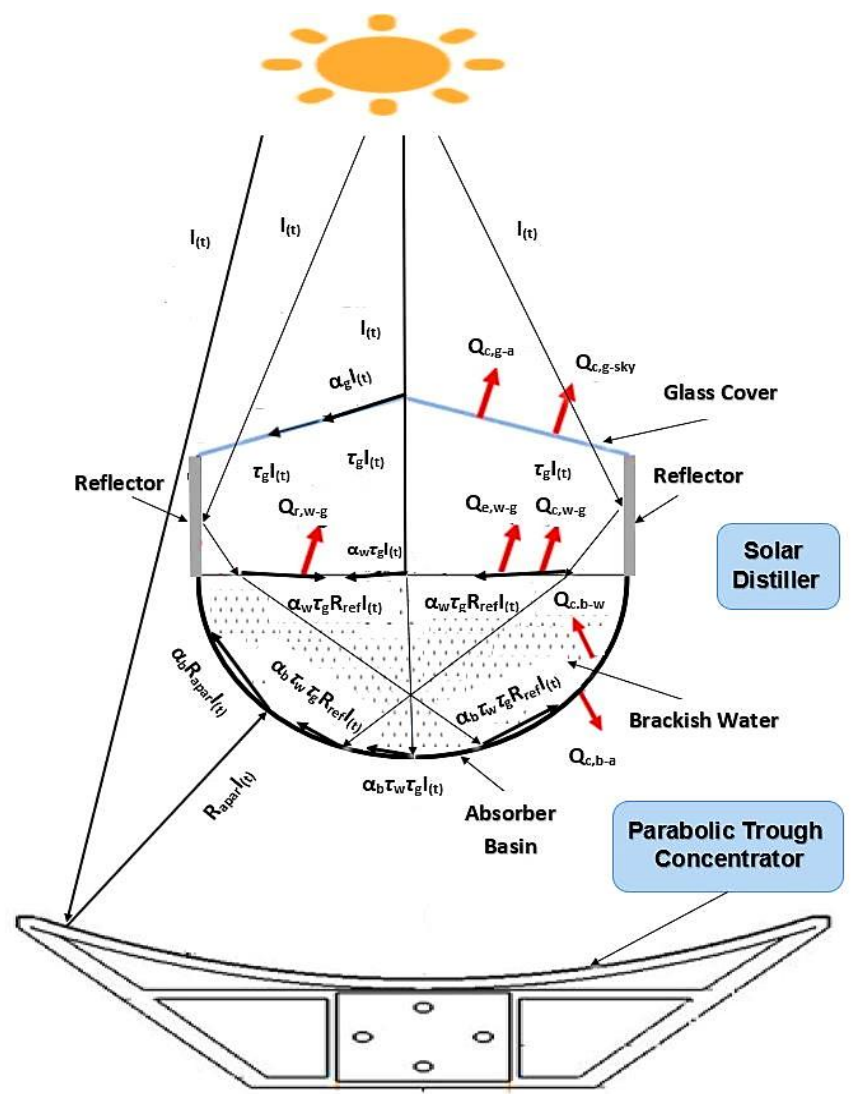

Fig. 2 The heat transfer paths of the distiller with a solar concentrator and internal reflectors

\subsection{Energy balance equations}

\subsubsection{Energy balance equation for glass cover}

The glass cover's energy balance equation for the conventional distiller, the distiller with internal reflectors, the distiller with a solar concentrator, the distiller with a solar concentrator and internal reflectors is as follows:

$$
C_{p g} M_{g} \frac{d T_{g}}{d t}=\left(\alpha_{g} A_{g} I_{(t)}+Q_{c, w-g}+Q_{e, w-g}+Q_{r, w-g}\right)-\left(Q_{c, g-a}+Q_{r, g-s k y}\right)
$$

where $C_{p g}, M_{g}, T_{g}, \alpha_{g}, A_{g}$, and $I_{(t)}$ are the specific heat of glass, the glass mass, the glass temperature, the glass absorptivity, the glass area, and the solar radiation, respectively. $Q_{c, w-g}, Q_{e, w-g}$, and $Q_{r, w-g}$ are the quantities of thermal transfer between the glass cover and the water by convection, evaporation, and radiation, respectively. $Q_{c, g_{-} a}$ indicates the quantity of thermal transfer between the glass cover and the air by convection. $Q_{r, g-s k y}$ indicates the thermal transfer quantity from the glass to the sky during radiation. The incident solar irradiance fraction absorbed by the glass cover is $\alpha_{g} A_{g} I_{(t)}$. 
The thermal transfer quantity generated by convection between the glass cover and the brackish water is described by the equation:

$$
Q_{c, w-g}=h_{c, w-g} A_{w}\left(T_{W}-T_{g}\right)
$$

where $h_{c, w-g}$ is the heat transfer coefficient by convection between the water and the glass [8, 20-21].

$$
h_{c, w-g}=0.884 \times\left[\left(T_{W}-T_{g}\right)+\frac{\left(P_{W}-P_{g}\right)\left(T_{W}+273\right)}{268.9 \times 10^{3}-P_{g}}\right]^{1 / 3}
$$

where $P_{g}$ and $P_{w}$ represent the saturating water vapor pressures at the glass cover and the water temperatures, respectively.

$$
\begin{aligned}
& P_{g}=\exp \left(25.317+\frac{5144}{T_{g}+273.15}\right) \\
& P_{W}=\exp \left(25.317+\frac{5144}{T_{W}+273.15}\right)
\end{aligned}
$$

The evaporation-induced energy transfer quantity between the glass cover and the brackish water is estimated as follows:

$$
Q_{e, w-g}=h_{e, w-g} A_{w}\left(T_{W}-T_{g}\right)
$$

The thermal transfer coefficient due by evaporation is $h_{e, w-g}$ using the following formula [8, 20-21]:

$$
h_{e, w-g}=0.016273 \times h_{c, w-g} \times \frac{P_{W}-P}{T_{W}-T_{g}}
$$

The following formula is used to compute the radiative heat transfer quantity between the water and the glass cover:

$$
Q_{r, w-g}=h_{r, w-g} A_{w}\left(T_{W}-T_{g}\right)
$$

Using Stefan-Boltzmann law, $h_{r, w-g}$ is the radiative thermal transfer coefficient of water to the glass cover [8, 20-21]:

$$
h_{r, w-g}=\varepsilon_{e f f} \sigma\left[\left(T_{W}+273\right)^{4}-\left(T_{g}+273\right)^{4}\right] /\left(T_{W}-T_{g}\right)
$$

where $\sigma$ and $\varepsilon_{\text {eff }}$ are the Stefan-Boltzmann constant $5.67 \times 10^{-8}\left(\mathrm{~W} / \mathrm{m}^{2} . \mathrm{k}\right)$ and the effective diffusivity, respectively [21].

$$
\varepsilon_{e f f}=\frac{1}{\frac{1}{\varepsilon_{w}}+\frac{1}{\varepsilon_{g}}-1}
$$

where $\varepsilon_{w}$ and $\varepsilon_{g}$ are the water and the glass emissivity, respectively. The convective heat transfer flux between the glass cover and the ambient air is as follows.

$$
Q_{c, g-a}=h_{c, g-a} A_{g}\left(T_{g}-T_{a}\right)
$$


The thermal transfer coefficient by convection is $h_{c, g-a}$, which can be calculated using the recommended equation by Johnson et al. [21]:

$$
h_{c, g-a}=\left\{\begin{array}{l}
2.8+3 V_{w d}, \text { if } V_{w d} \leq 5 \mathrm{~m} / \mathrm{sec} \\
2.8+3.8 V_{w d}, \text { if } V_{w d}>5 \mathrm{~m} / \mathrm{sec}
\end{array}\right\}
$$

The velocity of wind is measured in meters per second $\left(V_{w d}\right)$. The following is the equation for the radiative thermal amount losses from the glass cover to the sky:

$$
Q_{r, g-s k y}=h_{r, g-s k y} A_{g}\left(T_{g}-T_{s k y}\right)
$$

The coefficient of radiation thermal transfer $\left(h_{r, g-s k y}\right)$ is given by:

$$
h_{r, g-s k y}=\varepsilon_{g} \sigma\left[\left(T_{g}+273\right)^{4}-\left(T_{s k y}+273\right)^{4}\right] /\left(T_{g}-T_{s k y}\right)
$$

The sky temperature is $T_{\text {sky }}$ [21-22]:

$$
T_{s k y}=0.055 T_{a}^{1.5}
$$

\subsubsection{Energy balance equation for water}

The brackish water's energy balance equation for the conventional distiller and the distiller with a solar concentrator is:

$$
C_{p w} M_{w} \frac{d T_{w}}{d t}=\left(\alpha_{w} \tau_{g} A_{w} I_{(t)}+Q_{c, b-w}\right)-\left(Q_{c, w-g}+Q_{e, w-g}+Q_{r, w-g}\right)
$$

The brackish water's energy balance equation for the distiller with internal reflectors and the distiller with a solar concentrator and internal reflectors is as follows:

$$
C_{p w} M_{w} \frac{d T_{w}}{d t}=\left(\alpha_{w} \tau_{g} A_{w} I_{(t)}+\alpha_{w} \tau_{g} R_{r e f} A_{r e f} I_{(t)}+Q_{c, b-w}\right)-\left(Q_{c, w-g}+Q_{e, w-g}+Q_{r, w-g}\right)
$$

where $C_{p w}, M_{w}, T_{w}, \alpha_{w}, \tau_{g}, A_{w}, R_{r e f}$, and $A_{r e f}$ are the specific heat of water, the water mass, the water temperature, the water absorptivity, the glass transmissivity, the water area, the reflector reflectivity, and the reflector area, respectively. $\alpha_{w} \tau_{g} A_{w} I_{(t)}$ is the incident solar irradiation fraction absorbed by the water. $\alpha_{w} \tau_{g} A_{w} R_{r e f} A_{r e f} I_{(t)}$ is the solar energy reflected from the internal reflectors and absorbed by the water. $Q_{c, b-w}$ is the convective thermal loss from the absorber basin to the water.

$$
Q_{c, b-w}=h_{c, b-w} A_{b}\left(T_{b}-T_{w}\right)
$$

where $h_{c, b-w}$ is the convective thermal transfer coefficient between the water and basin that can be calculated using the Nusselt number correlation for horizontal cylinders [8, 23]:

$$
h_{c, b-w}=N u \times \frac{K_{w}}{L_{c}}
$$

$N u, G r$, and $P r$ are the Nusselt, Grashof, and Prandtl numbers, respectively, as calculated by:

$$
N u=a(G r \times \operatorname{Pr})^{n}
$$




$$
\begin{aligned}
& \operatorname{Gr}=\frac{\beta g L_{C}^{3} \rho^{2} \Delta T}{\mu^{2}}, \Delta T=T_{b}-T_{w}, \beta=\frac{1}{T_{i}+273}, T_{i}=\frac{T_{b}+T_{w}}{2} \\
& \operatorname{Pr}=\frac{\mu C_{P}}{K}
\end{aligned}
$$

Table 1 can be used to estimate the constant values for the Nusselt number equation. $K_{w}$ and $L_{c}$ indicate the thermal conductivity of water and the absorber's characteristic length, respectively.

Table 1 The Nusselt number equation's constant estimation $a$ and $n[8,23]$

\begin{tabular}{|c|c|c|c|}
\hline Surface & $(G r \times P r)$ & $a$ & $n$ \\
\hline Vertical plates/cylinders & $10^{4}-10^{9}$ & 0.59 & 0.25 \\
& $10^{9}-10^{12}$ & 0.13 & 0.33 \\
\hline Horizontal pipes & $10^{3}-10^{9}$ & 0.53 & 0.25 \\
\hline Horizontal plates & $10^{5}-2 \times 10^{7}$ & 0.54 & 0.25 \\
\hline Hertical plates, heated face up or cooled face down & $3 \times 10^{5}-3 \times 10^{10}$ & 0.27 & 0.25 \\
\hline
\end{tabular}

\subsubsection{Energy balance equation for half-cylinder basin}

The basin's energy balance equation for the conventional distiller is as follows:

$$
C_{p b} M_{b} \frac{d T_{b}}{d t}=\left(\alpha_{b} \tau_{g} \tau_{w} A_{b} I_{(t)}\right)-\left(Q_{c, b-w}+Q_{c, b-a}\right)
$$

The basin's energy balance equation for the distiller with a solar concentrator is as follows:

$$
C_{p b} M_{b} \frac{d T_{b}}{d t}=\left(\alpha_{b} \tau_{g} \tau_{w} A_{b} I_{(t)}+\alpha_{b} R_{p} A_{a p e r} I_{(t)}\right)-\left(Q_{c, b-w}+Q_{c, b-a}\right)
$$

The basin's energy balance equation for the distiller with internal reflectors is giving by:

$$
C_{p b} M_{b} \frac{d T_{b}}{d t}=\left(\alpha_{b} \tau_{g} \tau_{w} A_{b} I_{(t)}+\alpha_{b} \tau_{w} \tau_{g} R_{r e f} A_{r e f} I_{(t)}\right)-\left(Q_{c, b-w}+Q_{c, b-a}\right)
$$

The basin's energy balance equation for the distiller with a solar concentrator and internal reflectors is giving by:

$$
C_{p b} M_{b} \frac{d T_{b}}{d t}=\left(\alpha_{b} \tau_{g} \tau_{w} A_{b} I_{(t)}+\alpha_{b} R_{p} A_{a p e r} I_{(t)}+\alpha_{b} \tau_{w} \tau_{g} R_{r e f} A_{r e f} I_{(t)}\right)-\left(Q_{c, b-w}+Q_{c, b-a}\right)
$$

where $C_{p b}, M_{b}, T_{b}, \alpha_{b}, \tau_{w}, A_{b}, R_{p}$, and $A_{\text {aper }}$ are the specific heat of basin, the basin mass, the basin temperature, the basin absorptivity, the water transmissivity, the basin area, the PTC reflectivity, and the aperture of concentrator area, respectively. $\alpha_{b} \tau_{w} \tau_{g} A_{b} I_{(t)}$ is the incident solar irradiance fraction by the absorber basin. The solar irradiance reflecting from the PTC and received by the absorber basin is denoted by $\alpha_{b} R_{p} A_{a p e r} I_{(t)}$. The solar irradiance is reflected from the internal reflectors and the absorber basin is absorbed $\left(\alpha_{w} \tau_{g} A_{w} R_{r e f} A_{r e f} I_{(t)}\right)$. The amount of thermal transfer from the absorber to the ambient air is indicated by $Q_{c, b-a}$.

$$
Q_{c, b-a}=h_{c, b-a} A_{b}\left(T_{b}-T_{a}\right)
$$

where $h_{c, b-a}$ is the coefficient of convection thermal transfer determined by Eq. (12) [8]. 


\subsection{Hourly freshwater yield}

The hourly freshwater yield per $\mathrm{m}^{2}$ from the developed solar desalination unit is given by [3, 8]:

$$
M_{e v}=\frac{3600 \times Q_{e, w-g}}{h_{f g}}
$$

where $h_{f g}$ is the latent heat of water evaporation [24-25]:

$$
h_{f g}=\left\{\begin{array}{l}
3.165 \times\left[10^{6}-\left(761.6 \times T_{f}\right)\right], \text { if } T_{f} \geq 70 \mathrm{~m} / \mathrm{sec} \\
2.4935 \times\left\{10^{6}-\left[\left(947.79 \times T_{f}\right)+\left(0.013132 \times T_{f}{ }^{2}\right)-\left(0.0047974 \times T_{f}{ }^{3}\right)\right]\right\}, \text { if } T_{f}<70 \mathrm{~m} / \mathrm{sec}
\end{array}\right\}
$$

The mathematical mean value of the glass cover and water temperatures is used to calculate the temperature of the air-water mixture $T_{f}$.

$$
T_{f}=\frac{T_{g}+T_{w}}{2}
$$

\section{Results and Discussion}

In MATLAB software, the first-order differential Eqs. (1), (16), and (23) for the conventional distiller, the first-order differential Eqs. (1), (16), and (24) for the distiller with a solar concentrator, the first-order differential Eqs. (1), (17), and (25) for the distiller with internal reflectors, and the first-order differential Eqs. (1), (17), and (26) for the distiller with a solar concentrator and internal reflectors are written and analyzed utilizing the ode45 method. To solve them for all the temperatures of the glass cover, water, and absorber basin, simulations are conducted on the mathematical model. Through the MATLAB code, the freshwater yield is determined by using Eq. (28). The total duration of 12 hours for iteration starts from 6:22 to 17:22. The design and thermo-physical operational characteristics, as well as the constants employed in numerical calculations in this research, are illustrated in Table $2[6,20,26]$.

Fig. 3 depicts a flowchart of the general description of the overall methodology. Morocco's Rabat-Sale-Kenitra, which has a particularly fascinating geographical location, is taken into account in this study. The solar irradiance data is from the measurement taken by the European satellite Photovoltaic Geographical Information System (PVGIS) [8, 27-29] using metrological parameters in the zone of $34^{\circ} 01^{\prime} 53.34$ " North, 6 ${ }^{\circ} 50^{\prime} 39.72^{\prime \prime}$ West, with a height of $139 \mathrm{~m}$. 31 degrees is the best inclination angle [29]. The solar irradiance, wind speed, and ambient temperature are all evaluated over time in Fig. 4. Solar irradiance increases continually from $6: 22$ to a maximum at $12: 22\left(860 \mathrm{~W} / \mathrm{m}^{2}\right)$, following which it begins to decrease with time until 17:22. Furthermore, the differences in wind speed and ambient temperature over time are also taken into consideration. At $15: 22$, the highest wind speed is $4.85 \mathrm{~m} / \mathrm{s}$, and at $12: 22$, the maximum ambient temperature of $33^{\circ} \mathrm{C}$ is recorded [8].

Table 2 The thermo-physical characteristics and constants utilized in numerical calculations [6, 20, 26]

\begin{tabular}{|c|c|c|c|c|c|}
\hline Property & Value & Property & Value & Property & Value \\
\hline$M_{g}(\mathrm{~kg})$ & 5.374 & $C_{p, w}(\mathrm{~J} / \mathrm{kg} . \mathrm{K})$ & 4190 & $K_{b}(\mathrm{~W} / \mathrm{m} . \mathrm{K})$ & 204 \\
\hline$C_{p, g}(\mathrm{~J} / \mathrm{kg} . \mathrm{K})$ & 800 & $K_{w}(\mathrm{~W} / \mathrm{m} . \mathrm{K})$ & 0.67 & $\rho_{b}\left(\mathrm{~kg} / \mathrm{m}^{3}\right)$ & 2700 \\
\hline$K_{g}(\mathrm{~W} / \mathrm{m} . \mathrm{K})$ & 1.02 & $\rho_{w}\left(\mathrm{~kg} / \mathrm{m}^{3}\right)$ & 1002 & $\alpha_{b}$ & 0.90 \\
\hline$\rho_{g}\left(\mathrm{~kg} / \mathrm{m}^{3}\right)$ & 2530 & $\alpha_{w}$ & 0.05 & $A_{b}$ & 1.641 \\
\hline$\alpha_{g}$ & 0.05 & $\tau_{w}$ & 0.95 & $\varepsilon_{g}$ & 0.86 \\
\hline$\tau_{g}$ & 0.90 & $A_{w}$ & 0.9 & $\varepsilon_{w}$ & 0.95 \\
\hline$A_{g}$ & 1.062 & $M_{b}(\mathrm{~kg})$ & 17.722 & R_par & 0.95 \\
\hline$M_{w}(\mathrm{~kg})$ & 50 & $C_{p, b}(\mathrm{~J} / \mathrm{kg} . \mathrm{K})$ & 896 & R_ref & 0.95 \\
\hline
\end{tabular}




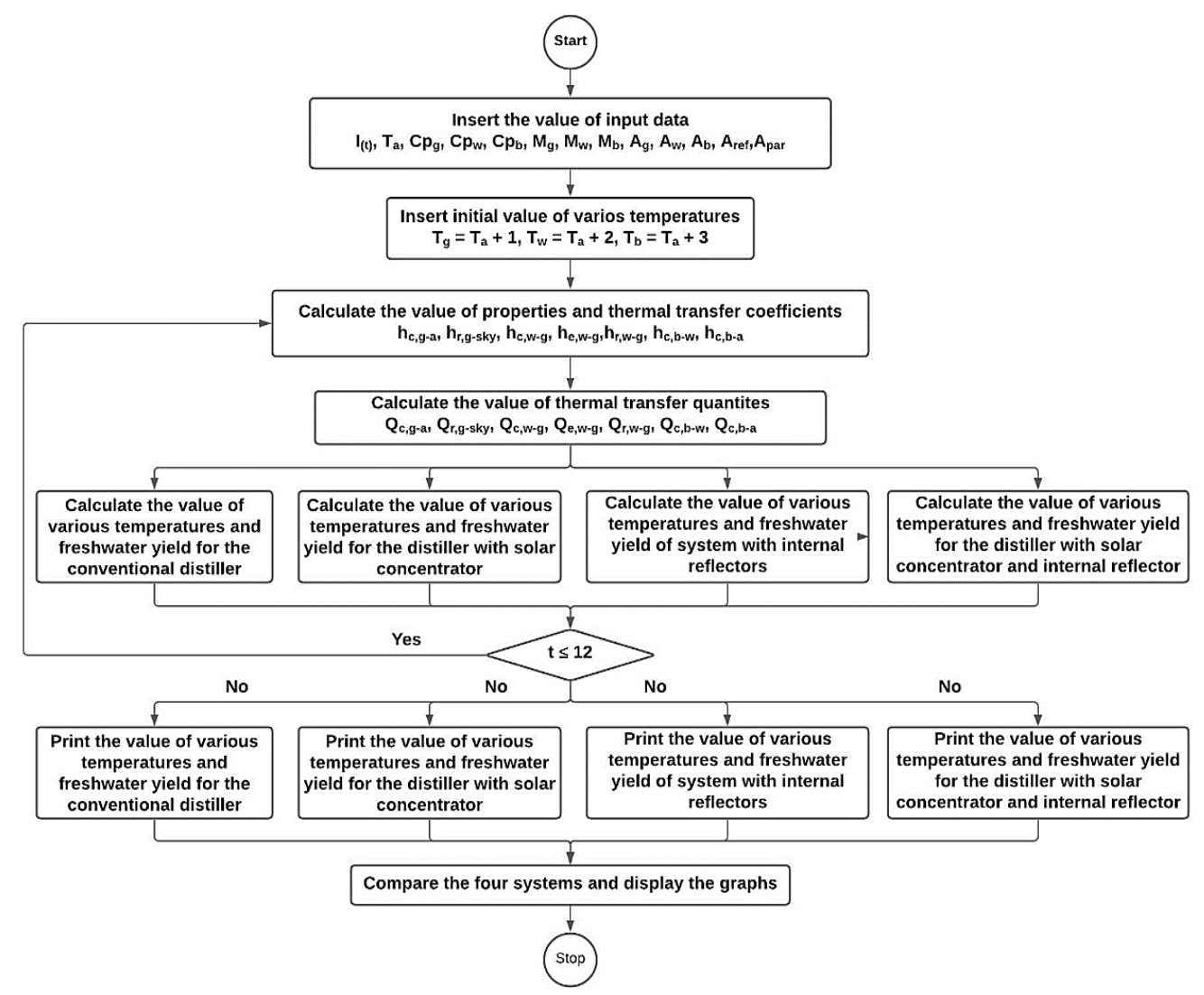

Fig. 3 Flowchart of the general description of the overall methodology

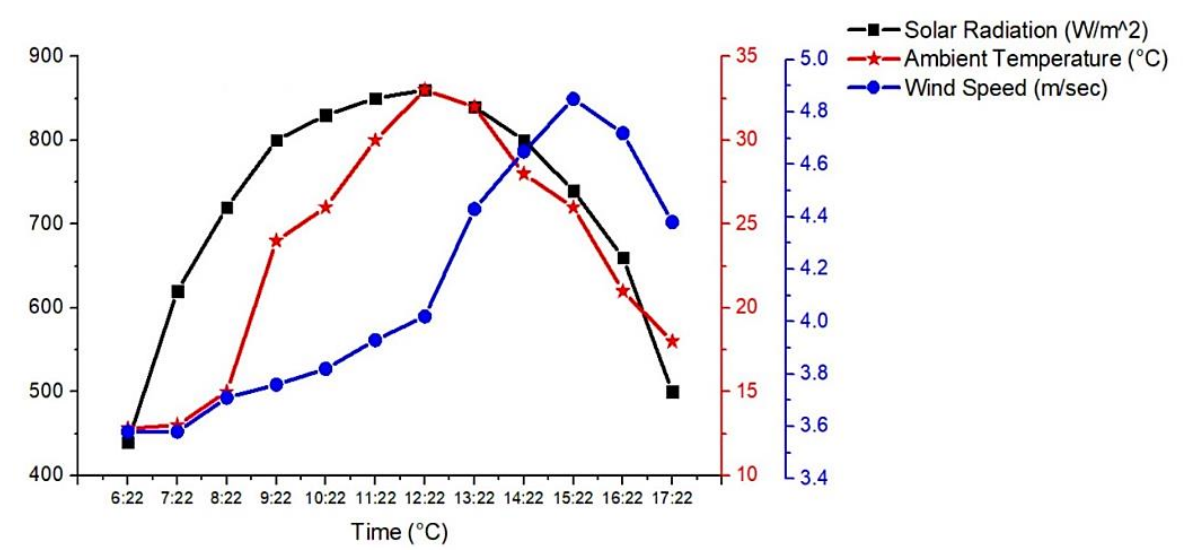

Fig. 4 Climate conditions estimated by PVGIS for the region of Rabat in Morocco

\subsection{The temperature and freshwater yield of the solar distiller with a solar concentrator and internal reflectors}

Fig. 5 depicts the temperature changes of all the components in the solar desalination unit with a solar concentrator and internal reflectors. It can be seen that the temperature of the absorber basin is higher than the temperature of water and glass due to the concentration of solar radiation falling on the basin by PTC and also the reflection of sunlight from the internal reflectors and its fall into the absorber basin, which leads to a rise in its temperature. As soon as the temperature of the basin rises, it leads to a thermal transfer from it to the water to be desalinated by convection, and there is also a thermal transfer from water to glass by convection, radiation, and evaporation.

The chart displays the temperature's relation with time. The temperature rises gradually from 6:22 to a maximum at 12:22 when solar radiation is at its highest, and then decreases slightly until 17:22. The temperature in the developed system's components rises as the solar radiation rises. The maximum temperature of the glass cover, brackish water, and half-cylinder basin in the solar desalination unit with a solar concentrator and internal reflectors are $79.33^{\circ} \mathrm{C}, 89.47^{\circ} \mathrm{C}$, and $101.7^{\circ} \mathrm{C}$, respectively. 


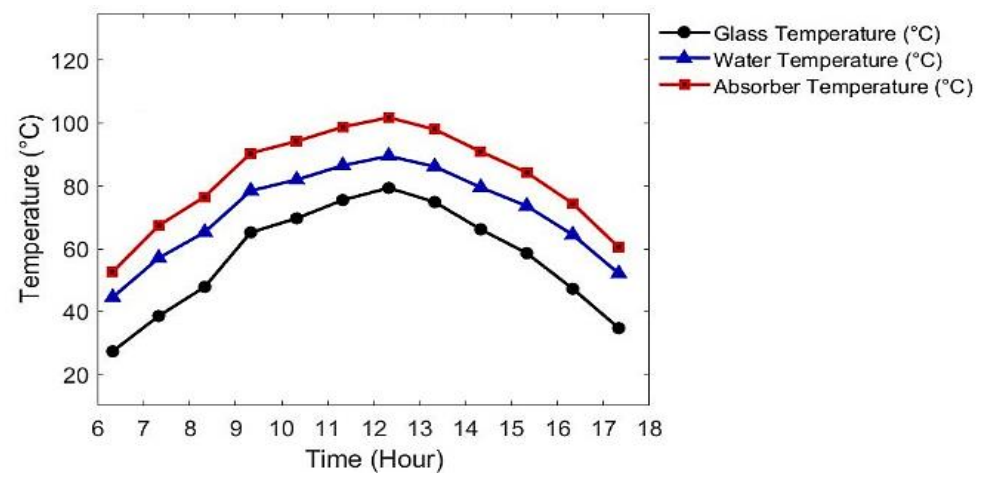

Fig. 5 Temperature evolution of the basin, water, and glass for the distiller with a solar concentrator and internal reflectors

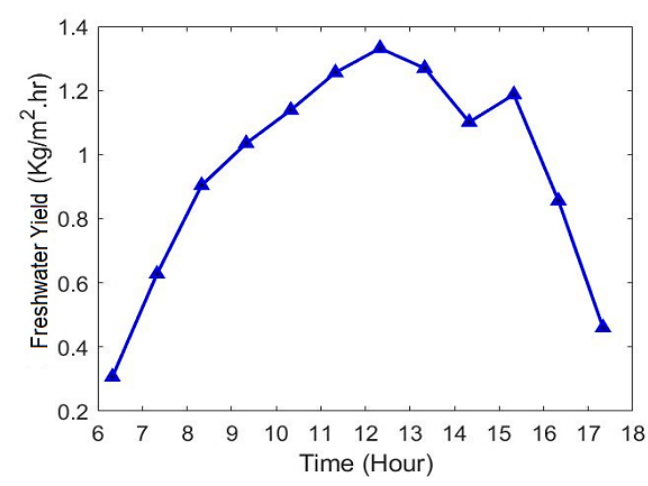

Fig. 6 Variation of the hourly freshwater yield for the distiller with a solar concentrator and internal reflectors

The reason for the high temperature of the absorber basin in the distiller with a solar concentrator and internal reflectors is because of the concentration and collection of large amounts of solar radiation falling on it from three places (the transparent glass cover and water, the internal reflectors, and the solar concentrator) and also the high absorptivity factor of the basin material.

Fig. 6 illustrates the evolution of the hourly freshwater yield for the distiller with a solar concentrator and internal reflectors over time. The use of internal reflectors leads to an increase in the amount of solar radiation reflected from them to the water, which leads to a rise in water temperature and an increase in the evaporation rate. The concentration of the reflected solar radiation from PTC to the absorber basin raises the absorber basin temperature. The heat transfer occurs between the basin and the water through convection, which leads to an increase in the water temperature and the evaporation rate again and thus increases the yield of the distilled water. The distilled water production begins at 6:22 and increases gradually until a maximum at 12:22 when solar radiation is at its highest, and then decreases slightly until 17:22. For the distiller with a solar concentrator and internal reflectors, the maximum hourly freshwater yield is $1.332 \mathrm{~kg} / \mathrm{m}^{2} . \mathrm{hr}$.

The difference in the temperature between the glass cover and basin water is considered a measure of buoyancy inside the distiller (thermal transfer through the natural convection of moist air inside the system). Thus, the higher the temperature, the larger the buoyant force, and hence the higher the thermal transfer rate with natural convection, and so the system's distilled yield increases [17].

\subsection{Comparison of the temperature and freshwater yield of four distillers: the conventional distiller, the distiller with internal reflectors, the distiller with a solar concentrator, and the distiller with a solar concentrator and internal reflectors}

Fig. 7 illustrates the comparison of the hourly temperature variations of the glass cover in the conventional distiller, the distiller with internal reflectors, the distiller with a solar concentrator, and the distiller with a solar concentrator and internal reflectors. All of the indicators have the same trend: they start to rise until they reach the maximum at 12:22. The maximum temperature reached by the glass cover in the conventional distiller, the distiller with internal reflectors, the distiller with a solar 
concentrator, and the distiller with a solar concentrator and internal reflectors are $37.26^{\circ} \mathrm{C}, 48.25^{\circ} \mathrm{C}, 63.56^{\circ} \mathrm{C}$, and $79.33^{\circ} \mathrm{C}$, respectively, at the maximum value of the solar radiation. They begin to fall gradually after this point and continue to do so until 17:22. It is noticed from Fig. 7 that the temperature of the glass cover is increased slightly by adding internal reflectors to the distiller because the area of internal reflectors is small. It is also observed that the temperature of the glass cover is increased dramatically by adding the solar concentrator because the area of the solar concentrator is large. Therefore, by adding the internal reflectors and the solar concentrator, the temperatures of the glass cover are increased, which are their highest values.

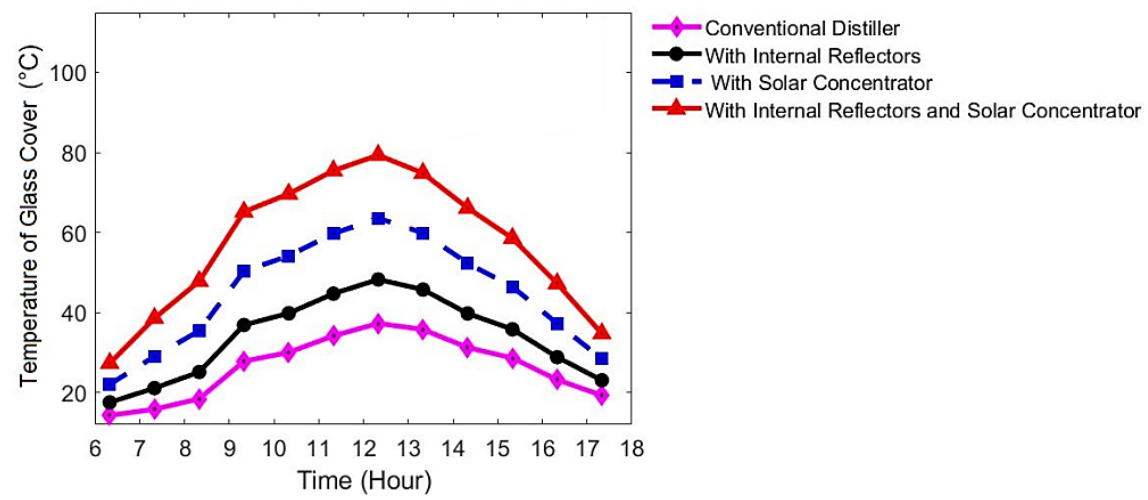

Fig. 7 Hourly temperature evolution of glass cover in four distillers

Fig. 8 shows the comparison of the hourly temperature variations of the brackish water in the conventional distiller, the distiller with internal reflectors, the distiller with a solar concentrator, and the distiller with a solar concentrator and internal reflectors as the use of the internal reflectors and/or the solar concentrator leads to an increase in water temperature, which leads to an increase in water evaporation. The maximum value of temperature attained by the brackish water in the conventional distiller, the distiller with internal reflectors, the distiller with a solar concentrator, and the distiller with a solar concentrator and internal reflectors are $46.15^{\circ} \mathrm{C}, 60.57^{\circ} \mathrm{C}, 75.75^{\circ} \mathrm{C}$, and $89.47^{\circ} \mathrm{C}$, respectively, at the maximum value of the solar radiation. The reasons that lead to an increase in the water temperature of four distillers are as same as the reasons that lead to an increase in the temperature of the glass cover, which are presented in the explanation of Fig. 7. The brackish water acquires the heat in general from the incident solar radiation from the transparent glass cover, or the solar radiation reflected from the reflectors, and also from the absorber basin by the heat transfer by convection, and the heat loss occurs between the water and the glass by the heat transfer by convection, radiation, and evaporation.

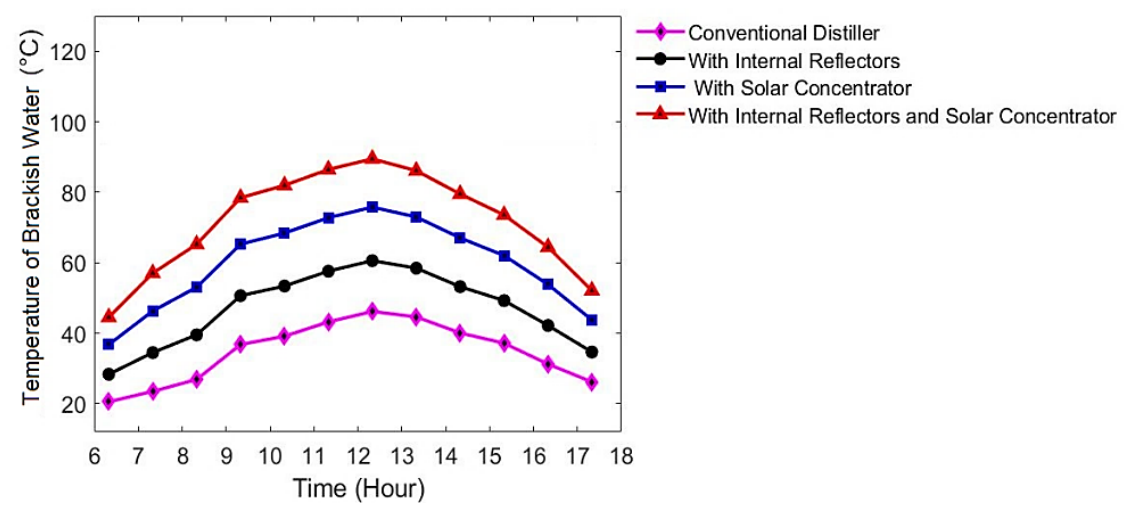

Fig. 8 Hourly temperature evolution of brackish water in four distillers

Fig. 9 illustrates the comparison of the hourly temperature variations of the absorber basin in the conventional distiller, the distiller with internal reflectors, the distiller with a solar concentrator, and the distiller with a solar concentrator and internal reflectors. The maximum value of temperature attained by the absorber basin in the conventional distiller, the distiller with internal reflectors, the distiller with a solar concentrator, and the distiller with a solar concentrator and internal reflectors are $49.94^{\circ} \mathrm{C}, 67.4^{\circ} \mathrm{C}, 85.84^{\circ} \mathrm{C}$, and $101.7^{\circ} \mathrm{C}$. It is noted from the maximum value of the absorber basin temperature that by adding 
internal reflectors the maximum temperature is increased by $34.96 \%$ compared to the conventional distiller, by adding the solar concentrator the maximum temperature is increased by $73.45 \%$ compared to the conventional distiller, and by adding the solar concentrator and internal reflectors the maximum temperature is increased by $105.50 \%$ compared to the conventional distiller.

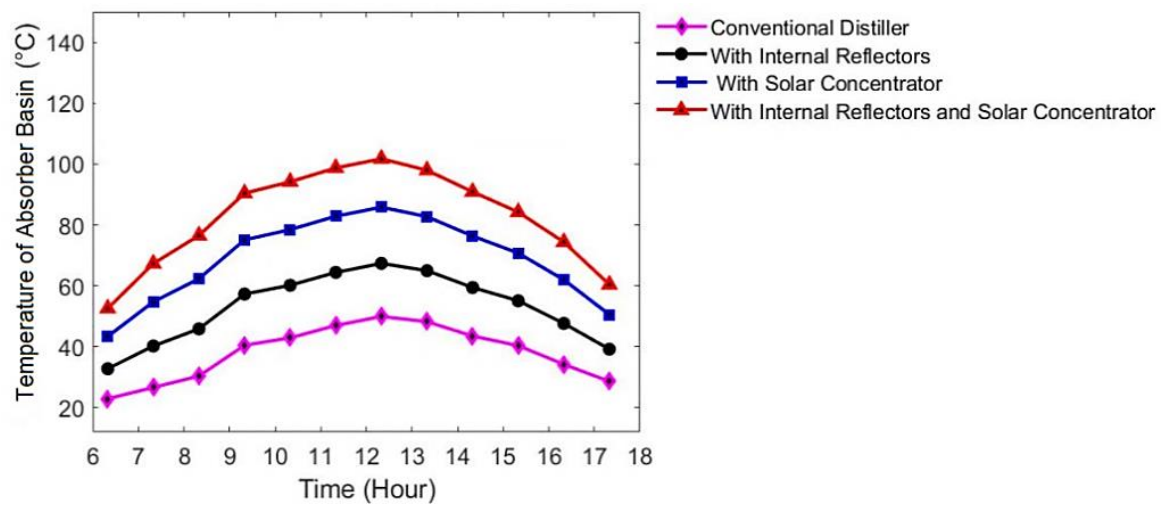

Fig. 9 Hourly temperature variation of absorber basin in four distillers

From Figs. 7-9, it is noticed that the temperature of the glass, water, and basin in the distiller with a solar concentrator and internal reflectors are the highest because the solar radiation is reflected from the solar concentrator and internal reflectors as well as from the transparent glass cover, which leads to an increase in the amount of solar radiation affecting the developed distiller.

Fig. 10 shows the comparison of the hourly variance in the freshwater yield for the conventional distiller, the distiller with internal reflectors, the distiller with a solar concentrator, and the distiller with a solar concentrator and internal reflectors. The maximum values of hourly freshwater yield are $0.169 \mathrm{~kg} / \mathrm{m}^{2} . \mathrm{hr}, 0.506 \mathrm{~kg} / \mathrm{m}^{2} . \mathrm{hr}, 1.07 \mathrm{~kg} / \mathrm{m}^{2} . \mathrm{hr}$, and $1.332 \mathrm{~kg} / \mathrm{m}^{2} . \mathrm{hr}$ for the conventional distiller, the distiller with internal reflectors, the distiller with a solar concentrator, and the distiller with a solar concentrator and internal reflectors, respectively. It can be seen from the maximum values of the freshwater yield of four distillers that by adding a solar concentrator and internal inverters the maximum value of the freshwater yield is increased by $688.17 \%$ compared to the conventional distiller, by adding a solar concentrator and internal reflectors the maximum value of the freshwater yield is improved by $199.41 \%$ compared to the conventional distiller, and by adding a solar concentrator the maximum value of the freshwater yield is increased by $533.14 \%$ compared to the conventional distiller.

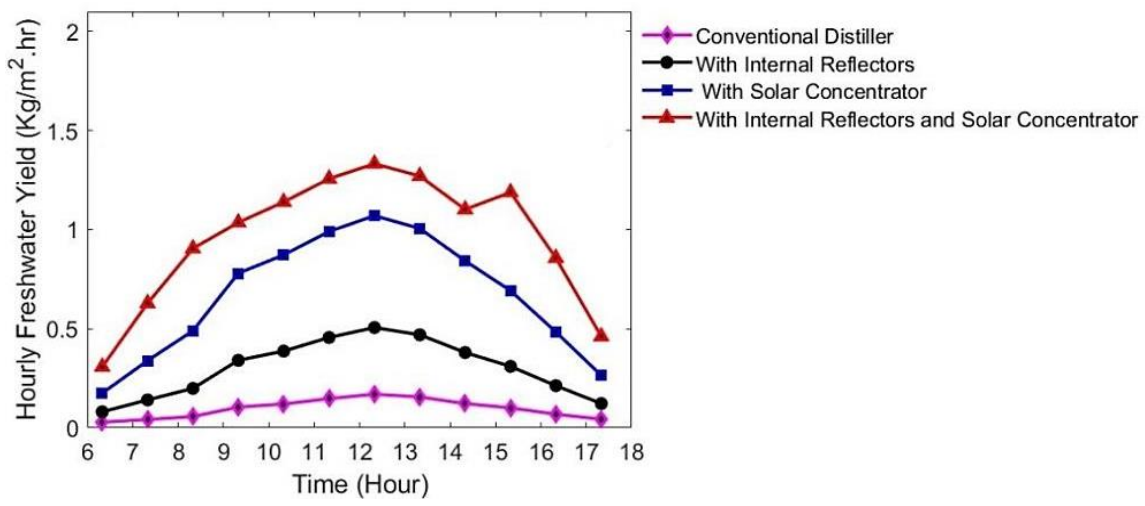

Fig. 10 Hourly variation of freshwater yield in four distillers

Fig. 11 illustrates the comparison of the cumulative freshwater yield for the conventional distiller, the distiller with internal reflectors, the distiller with a solar concentrator, and the distiller with a solar concentrator and internal reflectors. The cumulative freshwater yields are $1.16 \mathrm{~kg} / \mathrm{m}^{2}$. day, $3.60 \mathrm{~kg} / \mathrm{m}^{2}$.day, $8 \mathrm{~kg} / \mathrm{m}^{2}$.day, and $11.48 \mathrm{~kg} / \mathrm{m}^{2}$.day for the conventional distiller, the distiller with internal reflectors, the distiller with a solar concentrator, and the distiller with a solar concentrator and internal reflectors, respectively. It is noticeable from the values of the cumulative freshwater yield of four distillers that the cumulative yield of the distiller with the solar concentrator and internal reflectors is increased by $43.5 \%$ compared to the distiller with a solar concentrator. Adding the solar concentrator for the distiller improves the cumulative yield by $122 \%$ 
compared with the distiller with internal reflectors. The cumulative freshwater yield is improved by $210 \%, 589.66 \%$, and $889.66 \%$ for the distiller with internal reflectors, the distiller with a solar concentrator, and the distiller with a solar concentrator and internal reflectors, compared to a conventional distiller, respectively.

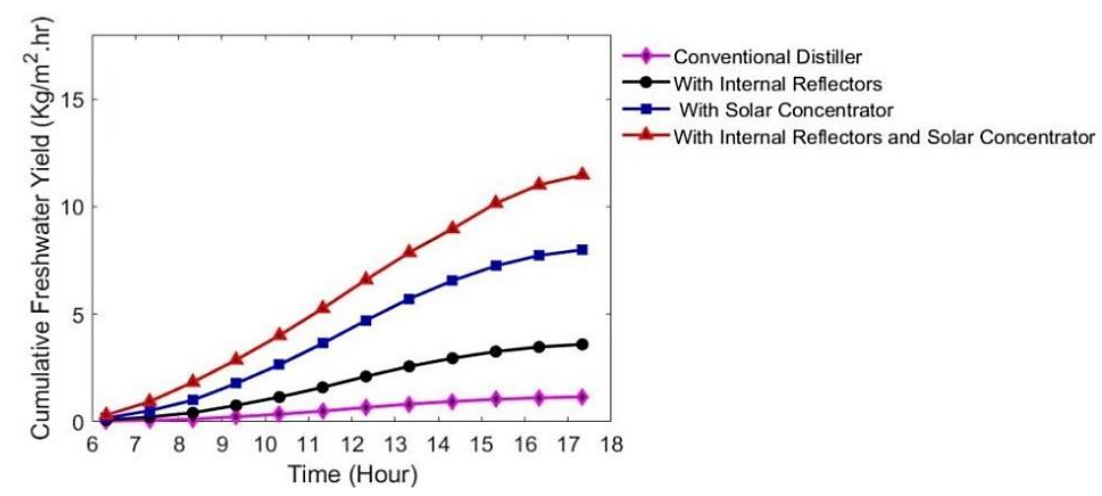

Fig. 11 Hourly variation of cumulative freshwater yield in four distillers

\section{Economic Analysis}

By estimating the life cycle cost (LCC), the full economic analysis is explored to show the effect of using the solar concentrator or/and the internal reflectors on the total cost of freshwater yield produced from the four solar distillers. The total freshwater production cost per kilogram $(T F P C / \mathrm{kg})$ is calculated using the following equations $[17,26]$.

$$
T F P C=\frac{T A C}{A F Y}
$$

where $T A C$ and $A F Y$ are the total annual cost and the annual freshwater yield, respectively $[17,26]$.

$$
T A C=A F C+A M C-A S V
$$

where $A F C$ and $A S V$ are the annual fixed cost and the annual salvage value, respectively [17, 26].

$$
A F C=F \times C R F
$$

where $A M C$ is the annual maintenance cost [26].

$$
\begin{aligned}
& A M C=0.15 \times A F C \\
& A S F=S \times S F F
\end{aligned}
$$

where $F, C R F, S$, and $S F F$ are the fixed cost, the capital recovery factor, the salvage value taken $20 \%$ of the fixed cost, and the sinking fund factor, respectively $[17,26]$.

$$
\begin{aligned}
& \text { CRF }=\frac{i \times(1+i)^{n}}{(1+i)^{n}-1} \\
& S F F=\frac{i}{(1+i)^{n}-1}
\end{aligned}
$$

The life years of the system $(n)$ and the interest per year $(i)$ are estimated to be 10 years and $12 \%$, respectively, in this analysis $[17,26]$. The total cost of freshwater production per kilogram generated by the conventional distiller, the distiller with internal reflectors, the distiller with a solar concentrator, and the distiller with a solar concentrator and internal reflectors are 0.113 , $0.047,0.055$, and $0.042 \$ / \mathrm{kg}$, respectively, depending on the cost of freshwater production per kilogram data shown in Table 3. 
Table 3 Cost of freshwater production per kilogram data for four distillers

\begin{tabular}{|c|c|c|c|c|}
\hline Items & $\begin{array}{c}\text { The conventional } \\
\text { distiller }\end{array}$ & $\begin{array}{c}\text { The distiller with } \\
\text { internal reflectors }\end{array}$ & $\begin{array}{c}\text { The distiller with the } \\
\text { solar concentrator }\end{array}$ & $\begin{array}{c}\text { The distiller with the } \\
\text { solar concentrator and } \\
\text { internal reflectors }\end{array}$ \\
\hline Fixed cost, \$ & 249 & 319 & 839 & 909 \\
\hline Annual fixed cost, \$ & 44.07 & 56.46 & 148.49 & 160.88 \\
\hline Annual maintenance cost, \$ & 6.61 & 8.47 & 22.27 & 24.13 \\
\hline The salvage value & 49.80 & 63.80 & 167.80 & 181.80 \\
\hline Annual salvage value, \$ & 2.84 & 3.64 & 9.56 & 10.36 \\
\hline Total annual cost, \$ & 47.84 & 61.29 & 161.20 & 4,190 \\
\hline $\begin{array}{c}\text { Annual freshwater } \\
\text { production, kg/m } / \mathrm{year}\end{array}$ & 423.40 & 1,314 & 2,920 & 0.05 \\
\hline $\begin{array}{c}\text { Total freshwater production } \\
\text { cost per kg, \$/kg }\end{array}$ & 0.113 & 0.047 & 0.055 & 0.042 \\
\hline
\end{tabular}

According to the economic analysis, the overall cost of freshwater production per kilogram generated from the distiller with internal reflectors, the distiller with a solar concentrator, and the distiller with a solar concentrator and internal reflectors are reduced by $58.4 \%, 51.3 \%$, and $62.8 \%$, respectively, compared to the conventional distiller.

\section{Comparison with Previously Published Researches}

The comparison between the present results and the results of previously published researches is performed to illustrate the effects of using the solar concentrator or/and internal reflectors and their influence on the cumulative output of the solar desalination units. Table 4 shows the comparison of the findings in this study with those in previous studies based on daily yield and freshwater cost. Using the solar concentrator or/and internal reflectors to boost the performance of the conventional solar distiller is very efficient.

Table 4 Comparison with previous researches

\begin{tabular}{|c|c|l|c|c|}
\hline Ref. & System type & \multicolumn{1}{|c|}{ Enhancement techniques } & $\begin{array}{c}\text { The daily yield } \\
\left(\mathrm{Kg} / \mathrm{m}^{2} . \text { day }\right)\end{array}$ & $\begin{array}{c}\text { The freshwater cost } \\
(\$ / \mathrm{kg})\end{array}$ \\
\hline$[13]$ & Solar still & - External reflectors & 4.03 & - \\
\hline$[15]$ & Corrated solar still & - Wick and reflector & 6 & 0.025 \\
\hline$[17]$ & Hemispherical distiller & $\begin{array}{l}\text { - Reflective aluminum foil sheet } \\
\text { - Reflective mirror }\end{array}$ & 6.76 & 0.0071 \\
\hline \multirow{2}{*}[18]{} & Double-slope single-basin & - Internal and external modifications & 5.13 & 0.0062 \\
\hline$[19]$ & Solar still & - Reflective mirrors & 4.9 & 0.022 \\
\hline$[21]$ & Srays solar still & - Frensel lens & 9.22 & 0.021 \\
\hline \multirow{2}{*}{ This } & Solar desalill & - Internal reflectors & 3.60 & 0.014 \\
\hline study & & - Solar concentrator & 11.48 & 0.047 \\
\hline
\end{tabular}

\section{Conclusions}

This research leads to useful conclusions:

(1) The internal reflectors and the solar concentrator play a vital role to increase the temperature of glass cover, brackish water, and absorber basin in the solar distiller.

(2) The temperature of glass cover, water, and basin in the solar desalination unit with the solar concentrator or/and internal reflectors are higher than the one in the conventional distiller. 
(3) The performance of the solar desalination unit with the solar concentrator or/and internal reflectors is better than the one of the conventional distiller. The daily freshwater yield of the conventional distiller, the distiller with internal reflectors, the distiller with a solar concentrator, and the distiller with a solar concentrator and internal reflectors are $1.16 \mathrm{~kg} / \mathrm{m} 2 . \mathrm{day}, 3.60$ $\mathrm{kg} / \mathrm{m} 2$.day, $8 \mathrm{~kg} / \mathrm{m} 2$.day, and $11.48 \mathrm{~kg} / \mathrm{m} 2$. day, respectively.

(4) Using the solar concentrator, the internal reflectors, and the solar concentrator and internal reflectors improve the cumulative freshwater yield by $210 \%, 589.66 \%$, and $889.66 \%$ compared with the conventional distiller.

(5) Utilizing the distiller with the solar concentrator improves the cumulative yield by $122 \%$ compared with the distiller with internal reflectors.

(6) The area of the internal reflectors cannot be increased more than the total area of the internal surfaces of the solar distiller. In contrast, the increase in the area of the solar concentrator is available as required.

(7) The economic study indicate that the cost of freshwater produced from the distiller with internal reflectors, the distiller with a solar concentrator, and the distiller with a solar concentrator and internal reflectors are reduced by $58.4 \%, 51.3 \%$, and $62.8 \%$ respectively compared to the cost using the conventional distiller.

\section{Suggestions and Recommendations}

In conclusion, the findings suggest that using reflectors and concentrators can considerably improve the solar distillers' performance, which is especially advantageous in rural places. Therefore, the authors recommend the manufacture and use of the solar distillers with solar concentrators or/and internal reflectors.

It is proposed that future research in remote areas further investigate the use of certain techniques to enhance the performance of solar distillers. The solar concentration and reflector modules, for example, can be used with solar distillers to increase the evaporation and condensation rates and therefore increase the freshwater yield of distillers.

\section{Conflicts of Interest}

The authors declare no conflict of interest

\section{References}

[1] M. Khan and I. Nawaz, "To Enhance the Performance of Solar Still with Reflectors," International Journal of Advanced Research, vol. 5, no. 3, pp. 1208-1216, March 2017.

[2] H. Amiri, M. Aminy, M. Lotfi, and B. Jafarbeglo, "Energy and Exergy Analysis of a New Solar Still Composed of Parabolic Trough Collector with Built-In Solar Still,” Renewable Energy, vol. 163, pp. 465-479, January 2021.

[3] Y. Sarray, N. Hidouri, A. Mchirgui, and A. B. Brahim, "Study of Heat and Mass Transfer Phenomena and Entropy Rate of Humid Air Inside a Passive Solar Still,” Desalination, vol. 409, pp. 80-95, May 2017.

[4] M. E. H. Attia, A. E. Kabeel, M. Abdelgaied, and Z. Driss, "Productivity Enhancement of Traditional Solar Still by Using Sandbags of El Oued, Algeria,” Heat Transfer, vol. 50, no. 1, pp. 768-783, January 2021.

[5] A. E. Kabeel, M. Abdelgaied, and A. Eisa, "Enhancing the Performance of Single Basin Solar Still Using High Thermal Conductivity Sensible Storage Materials,” Journal of Cleaner Production, vol. 183, pp. 20-25, May 2018.

[6] M. Ghodbane and B. Boumeddane, "A Numerical Analysis of the Energy Behavior of a Parabolic Trough Concentrator," Journal of Fundamental and Applied Sciences, vol. 8, pp. 671-691, September 2016.

[7] A. Hepbasli and Z. Alsuhaibani, "A Key Review on Present Status and Future Directions of Solar Energy Studies and Applications in Saudi Arabia,” Renewable and Sustainable Energy Reviews, vol. 15, no. 9, pp. 5021-5050, December 2011.

[8] M. Mohammed and T. J. Mourad, “Theoretical Analysis of a New Design of a Concentration Based Solar Distiller," E3S Web of Conferences, vol. 234, 00003, 2021. 
[9] T. Arunkumar, R. Velraj, A. Ahsan, A. J. N. Khalifa, S. Shams, D. Denkenberger, et al., "Effect of Parabolic Solar Energy Collectors for Water Distillation," Desalination and Water Treatment, vol. 57, no. 45, pp. 21234-21242, September 2016.

[10] N. E. Gharbi, H. Derbal, S. Bouaichaoui, and N. Said, “A Comparative Study Between Parabolic Trough Collector and Linear Fresnel Reflector Technologies,” Energy Procedia, vol. 6, pp. 565-572, April 2011.

[11] Mulyanef, Duskiardi, K. Sopian, Kaidir, and Z. Rahman, "Performance Experimental Study of Solar Still with Reflector to Produce Fresh Water and Salt," MATEC Web of Conferences, vol. 248, 01004, 2018.

[12] S. Umar and U. K. Muhammad, "Effect of Reflecting Booster on the Performance Evaluation of Solar Still," International Journal of Environment and Bioenergy, vol. 8, no. 3, pp. 108-116, 2013.

[13] A. Z. Al-Garni, "Effect of External Reflectors on the Productivity of a Solar Still During Winter," Journal Energy Engineering, vol. 140, no. 1, 04013002, March 2014.

[14] M. Khan and M. Mustafa, "Solar Still Distillate Productivity Enhancement by Using Reflector and Design Optimization," Innovative Energy and Research, vol. 8, no. 4, 1000222, 2019.

[15] Z. M. Omara, A. E. Kabeel, A. S. Abdullah, and F. A. Essa, "Experimental Investigation of Corrugated Absorber Solar Still with Wick and Reflectors," Desalination, vol. 381, pp. 111-116, March 2016.

[16] A. Khechekhouche, A. E. Kabeel, B. Benhaoua, M. E. H. Attia, and E. M. S. El-Said, "Traditional Solar Distiller Improvement by a Single External Refractor under the Climatic Conditions of the El Oued Region, Algeria," Desalination and Water Treatment, vol. 177, pp. 23-28, February 2020.

[17] M. E. H. Attia, M. Abdelgaied, and A. Abdullah, "A Comparative Study of the Effect of Internal Reflectors on a Performance of Hemispherical Solar Distillers: Energy, Exergy, and Economic Analysis," Sustainable Energy Technologies and Assessments, vol. 47, 101465, October 2021.

[18] S. J. P. Gnanaraj and V. Velmurugan, “An Experimental Study on the Efficacy of Modifications in Enhancing the Performance of Single Basin Double Slope Solar Still,” Desalination, vol. 467, pp. 12-28, October 2019.

[19] A. S. Abdullah, M. M. Younes, Z. M. Omara, and F. A. Essa, "New Design of Trays Solar Still with Enhanced Evaporation Methods-Comprehensive Study," Solar Energy, vol. 203, pp. 164-174, June 2020.

[20] M. Bouzaid, O. Ansari, M. Taha-Janan, and M. Oubrek, "Experimental and Theoretical Analysis of a Novel Cascade Solar Desalination Still,” Fluid Dynamics and Materials Processing, vol. 14, no. 3, pp. 177-200, 2018.

[21] A. Johnson, L. Mu, Y. H. Park, D. J. Valles, H. Wang, P. Xu, et al., "A Thermal Model for Predicting the Performance of a Solar Still with Fresnel Lens,” Water, vol. 11, no. 9, 1860, September 2019.

[22] J. A. Duffie and W. A. Beckman, Solar Engineering of Thermal Processes, 4th ed. Hoboken: John Wiley, 2013.

[23] A. Z. Hafez, A. Soliman, K. A. El-Metwally, and I. M. Ismail, "Solar Parabolic Dish Stirling Engine System Design, Simulation, and Thermal Analysis," Energy Conversion and Management, vol. 126, pp. 60-75, October 2016.

[24] H. A. Zoori, F. F. Tabrizi, F. Sarhaddi, and F. Heshmatnezhad, "Comparison Between Energy and Exergy Efficiencies in a Weir Type Cascade Solar Still,” Desalination, vol. 325, pp. 113-121, September 2013.

[25] M. S. Yousef and H. Hassan, "Energetic and Exergetic Performance Assessment of the Inclusion of Phase Change Materials (PCM) in a Solar Distillation System," Energy Conversion and Management, vol. 179, pp. 349-361, January 2019.

[26] R. Dhivagar, M. Mohanraj, K. Hidouri, and Y. Belyayev, "Energy, Exergy, Economic and Enviro-Economic (4E) Analysis of Gravel Coarse Aggregate Sensible Heat Storage-Assisted Single-Slope Solar Still,” Journal of Thermal Analysis Calorimetry, vol. 145, no. 2, pp. 475-494, May 2020.

[27] M. Súri, T. A. Huld, E. D. Dunlop, M. Albuisson, and L. Wald, "Online Data and Tools for Estimation of Solar Electricity in Africa: the PVGIS Approach,” 21st European Photovoltaic Solar Energy Conference, pp. 4-8, September 2006.

[28] P. G. Kale and R. Tarai, "Development of Rasterized Map Using PVGIS for Assessment of Solar PV Energy Potential of Odisha," International Journal of Renewable Energy Research, vol. 6, no. 1, pp. 61-73, March 2016.

[29] S. E. Lachhab, A. Bliya, E. Al Ibrahmi, L. Dlimi, "Theoretical Analysis and Mathematical Modeling of a Solar Cogeneration System in Morocco,” AIMS Energy, vol. 7, no. 6, pp. 743-759, 2019.

Copyright $\subset$ by the authors. Licensee TAETI, Taiwan. This article is an open access article distributed under the terms and conditions of the Creative Commons Attribution (CC BY-NC) license (https://creativecommons.org/licenses/by-nc/4.0/). 